\title{
Rational Escalation: The Real Option Perspective
}

\author{
Dmitriy V. Chulkov, (E-mail: dchulkov@iuk.edu), Indiana University Kokomo
}

\begin{abstract}
Escalation is generally defined in investment context as continuation of an investment project after receiving negative signals about the outcome. This study demonstrates that under conditions of uncertainty about project outcome there is a rational incentive for the manager to continue a project to receive more information. Taking this real option on continuing the project has value for the firm. Simulations results from the option value model of investment demonstrate that likelihood of escalation is higher when signals have higher quality which increases the value of getting an additional signal. Likelihood of escalation also increases when the prior expectation of success is low, and when project termination cost is low. Continuing the project to receive additional information is shown to be more profitable than the simple net present value rule that excludes option value. The model implies that escalation may be value-maximizing for the firm, and managers should not automatically be discouraged to continue a project when new signals about its success may appear in the future.
\end{abstract}

\section{INTRODUCTION}

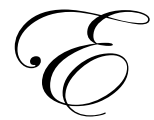

scalation of commitment involves continued allocation of resources in the face of negative feedback (Brockner, 1992). Management literature reports high estimates of the cost of escalated projects for businesses. Case studies described below show instances of multi-billion-dollar write-offs due to cancelled projects (Ross and Staw, 1986, 1993). Keil and Mann (1997) estimated based on survey data that 30 to $40 \%$ of all IS projects encounter some degree of escalation.

The escalation pattern of behavior is usually seen as irrational. The prevailing view is that escalation goes contrary to the basic principles of economics. Some authors go as far as suggest that escalation highlights the inadequacy of economic decision theories (e.g. Goltz, 2000). Consider the following quote representative of this view.

"Logically, one might expect behavior in escalation situations to follow a process akin to conventional economic decision making. For example, when questionable or negative outcomes are received they should trigger reexamination of the course of action, with commitment being maintained or reduced, depending on the utility of persistence versus withdrawal. Such an economic decision model would, however, predict that individuals or organizations seldom get locked into losing courses of action. According to economic logic, we might expect escalation cycles to be quickly disappearing events, since reexamination of a course of action should become increasingly vigilant as negative outcomes are received, and the utility of a course of action should become increasingly negative as losses build up. Thus, given the precepts of economic decision making, one is compelled to ask why cycles of escalation afflict both individuals and organizations." (Ross and Staw, 1986)

Attempts to demonstrate that escalation-type behavior may in fact arise from rational economic decision making have relied on the use of principal-agent models. Escalation in such setup follows from the desire of manager to protect reputation (e.g. Kanodia et al., 1989). Barron, Chulkov and Waddell (2007) use a reputationbased model of escalation to link project termination decisions and managerial turnover. This paper intends to show that an escalation pattern can follow from rational behavior by the manager in a real option context. 
Real option theory is concerned with investment projects that are similar in structure to financial assets (Dixit and Pindyck, 1994). Option valuation dates back to the work of Bachelier (1900), and accurate formulas for valuation of stock options have long been used (Black and Scholes, 1973). As the similarity between option contracts and investment projects became recognized, real option theory was extensively used in managerial analysis. For instance, Bowman and Hurry (1993) discuss implications of real option theory for strategy development. A call option involves the right to purchase the asset, but does not impose an obligation. Similarly, in an investment project, initial investment provides a chance to carry the project through to completion, without the obligation to continue if losses prevail. An investment project is thus analogous to an American call option, with the exercise price being the difference of salvage value and costs of stopping the project. At every stage of the project's development, the manager has a choice of continuing (exercising the option) or stopping the project, taking the salvage value, and paying the stopping cost. The expected value of the project at every stage entails the calculation of the value of stopping versus the value of continuing for one more period. Conventional net present value reasoning focusing on the weighted payoffs of success and failure may ignore the value of the option of stopping the project in the future. Among others, Robichek and Van Horne (1967) publicized the fact that option of stopping the project has value in the finance literature. Tiwana, Keil and Fichman (2006) demonstrated using experimental data collected from managers in 123 firms that managers recognize and value the presence of real options.

A number of psychological explanations for escalation-type behavior have been proposed in the literature. A key question appeared in some publications: "Are there (non-economic) factors that naturally lead people to become committed in escalation situations, or are post-hoc behavioral explanations attached to situations where reasonable decisions simply did not work out as planned?" (Ross and Staw, 1986) The implicit consensus in the managerial literature is that the former is the case. This study aims at presenting a model in support of the latter. Simulations of this real option model of investment show that escalation in the sense of project continuation after negative feedback is in fact to be expected from rational decision making by the manager.

While escalation is a multi-determined phenomenon that can be caused by non-economic factors, focusing solely on psychological and social reasons behind escalation may underestimate the economic forces that influence this phenomenon. The model presented below demonstrates the potential of a behavioral pattern consistent with escalation following from rational decision making in situations close to the cases of escalation described in the literature.

\section{OVERVIEW OF ESCALATION RESEARCH}

The views of escalation in the literature can generally be divided in two major groups treating the phenomenon as either a decision-theoretic, or a game-theoretic problem. In a game-theoretic context, escalation is defined as "two or more agents becoming locked in a decision process resulting in spending more resources than the outcome is worth" to either of them (Demange, 1992). An example of such behavior is Shubik's (1971) all-pay auction for a dollar. In such an auction, the players bid for a fixed prize. All bidders must pay their bids, but only the high bidder receives the prize. Bidding in such auctions escalates and often reaches values well above the prize value. Demange (1992) analyses this game showing how escalation can be justified in certain equilibria. The cited examples of escalation in a game-theoretic framework include arms races, competitions for government contracts.

Management literature focuses on escalation in a decision-theoretic context, looking at the behavior of a manager in a project selection problem. Escalation is generally described as follows. First, a decision-maker performs a choice between several projects under conditions of uncertainty about the outcome. The decision is followed by losses or negative signals. At this stage the decision-maker has an option of stopping the project or switching to another one. Having received the negative feedback, however, the decision-maker escalates the original commitment and continues the project.

Note that such escalation process requires that a series of sequential decisions associated with a course of action are undertaken, not just a single choice. Other features of the escalation process include the presence of negative feedback about the current course of action, the fact that the decision-maker has a choice of continuation or termination of the current policy, and the conditions of uncertainty about the outcomes of the course of action. 
Research on escalation in managerial and psychological fields concentrated on identifying the determinants of escalation. Staw and Ross $(1987,1989)$ present a structural grouping of the determinants of escalation, uniting them into four major classes: project (objective), psychological, social, and structural (organizational) determinants.

The first group of variables encompasses the objective economic characteristics of a project. They include the size and sequencing of benefits and costs associated with a project. In addition, when the setback to the project is temporary, as opposed to permanent, then escalation may be likely to occur. Early occurrence of negative information about the project or unexpected costs may lead to termination, while early successes followed by a gradual decline in the value of the project prompt commitment. Finally, it may be optimal to continue a losing project as long as the costs of termination exceed the losses from its completion. Examples of closing costs may include payments for terminated employees and penalties on unfulfilled contracts and leases.

Psychological determinants of escalation focus on a self-justification process that leads individuals to seek rationalization of prior actions and defend themselves against negative consequences of their behavior (Staw, 1976). Managers escalate commitment to a project in hope that a turnaround will prove the ultimate rationality of their behavior.

A social determinant of escalating commitment is the existence of social norms for managers. For instance, consistent managers are generally viewed as better ones (Staw and Ross, 1980). In addition, experiments by Brockner et al. (1984) found that individuals invested more in a project and kept commitment to it when others also committed themselves in such situation. This was seen as evidence that agents use modeling techniques in decision making, following the behavior of others.

Organizational determinants of escalation include the inertia that exists due to breakdowns in communications and ensures that even when a need is recognized it may not be acted upon swiftly. Project termination may also encounter interference from political forces. At the extreme, a project may become such an integral part of an organization so as to be institutionalized. Institutionalization is defined as embedding of a behavior into the norms and values of a group. Once institutionalized, a project is not even considered for rejection being so closely identified with the firm.

The consensus in the escalation literature is that while economic factors may be important at some stages of the escalation process affecting the magnitude of escalation, the decision to continue a project after negative feedback is irrational in itself and cannot be explained by conventional economic models. The following quote from Staw and Ross (1987) is representative of such views: "Such a decision model would not as much explain escalation behavior as provide a description of the process of escalation. Missing from the decision model are content variables that make persistence rather than withdrawal the choice of individuals in escalation situations". In contrast to this view, the model presented in the next section yields behavior consistent with escalation solely from the interaction of objective economic variables.

Staw and Ross (1987) recommend that a model of escalation be based upon the patterns of escalation observed in prototypical case studies of escalation. In line with this conclusion, the existing case studies of escalation are examined below to establish the common patterns of escalation behavior.

\section{Case Of Expo' 86 World Fair}

One of the first attempts to document and evaluate an escalated project was the study by Ross and Staw (1986) looking at the organization of the Expo'86 world fair in Vancouver, Canada. Holding the Expo in Vancouver was initially suggested in 1978. The project appeared profitable. In 1980 and 1981 a number of analysts prepared reports on the economics of the fair. The project was still viewed as "good business". The "worst case scenario" projected a $\$ 6$ million loss. Over the next years positive signals about the project revenue change to negative ones. In 1982 new estimates on the project were released, the budget increased to $\$ 370$ million, with a $\$ 12-15$ million deficit. On April 11, 1984, the director of Expo construction recommended that the project be cancelled due to projected losses and trade union resistance to current construction contracts. The provincial Premier Minister 
overruled this recommendation and continued the project. At this time the cost of project termination was already quite high, listed at $\$ 80$ million. Furthermore, there were rumors that federal government might sue to recover the funds provided for the project in case of termination, raising the stopping cost.

In 1984, a world fair was held in New Orleans. Due to similarities between the venues, the results of the New Orleans fair provided a new signal to the decision makers. This signal was strongly negative. The attendance at New Orleans fair was well below projections, the fair ended with a high budget deficit. Following a visit of Vancouver decision makers to New Orleans, the projected attendance for Expo' 86 was decreased, there were budget cuts as the budget was finalized at $\$ 802$ million, with a deficit of $\$ 311$ million. Then the project was carried through to completion.

In summary, the Expo started as a profitable project, the initial signals on the project revenues were positive. Later a series of negative signals were received, however the project was continued and executed at a loss. It should be noted that the extent of the losses of the Expo is not clear-cut. The budget of the exhibition does not account for all the benefits of the project. Ross and Staw (1986) mention that in 1982 the additional effect of the exhibition on the economy of British Columbia was estimated at $\$ 970$ million due to tourist revenues and creation of 15,000 man-years of jobs.

\section{Case Of The Shoreham Nuclear Power Plant}

Another case study due to the same authors (Ross and Staw, 1993) examines the construction of a nuclear power station in Shoreham, New York. The project was started in 1968 and the initial evaluation of the project was favorable. As construction began, several positive signals related to the project were received. In 1969, increases in the expected demand for electricity led to a rise in the projected capacity of the plant. The oil crisis of the early seventies made the production of nuclear energy even more attractive.

By the late 1970s, however, the construction ran behind schedule, and there were significant cost overruns reported. The main reason for the rising costs was attributed to new regulatory requirements. A 1977 report blames tighter environmental standards for $\$ 181$ million of increased spending. A series of delays saw the estimated completion date move from 1979 to 1983, as the total expenditure on the project reached $\$ 2.2$ billion. At this point, the cost of stopping the project increased significantly. Before fuel is loaded into a nuclear reactor, it is possible to sell the parts for salvage value reported in Ross and Staw (1993) in the \$100 million range. However, once operation is begun, not only does the reactor lose its salvage value, but also a substantial decontamination cost has to be incurred. Total increase in the cost of stopping is reported as at least $\$ 200$ million.

The final blow to the Shoreham project came on April 25, 1986, with the Chernobyl nuclear disaster. State and local governments increased their resistance to the project, and in 1988 the completed power plant was turned over to the state in return for a $\$ 2.5$ billion tax write-off. The plant was never put into operation even though the construction and testing were finished.

Clearly, the Shoreham story has a high degree of political and regulatory intervention. We can still observe the features of economic decision making in this case. The project was started after favorable evaluation. Initially there were several positive signals on the project's outcome. Then a series of negative signals were received as the project progressed and the costs built up. The project was finally terminated.

\section{CompuSys Software Automation Project}

Keil (1995) explores the decision by CompuSys, a large computer hardware company, to construct an automated system to help sales representatives produce error-free configurations. The system, called Config, was to reduce the costly fines paid to customers because of incorrect configurations. (The actual names of participating companies and individuals were disguised by Keil due to privacy considerations.) 
Keil (1995) reports summaries of management meetings devoted to the project, and evaluates the information presented at each meeting as either positive, negative, or ambiguous. The project was started in 1981, and continued through 1992. There were fourteen separate signals reported. The following is the timeline of the signals. The first signal was positive, the second was ambiguous, followed by a string of eight negative signals. Signals 11-13 were ambiguous, and finally after negative information (signal 14) in 1992, the project was terminated. This timeline of project signals, however, does not include three separate positive financial analyses of the Config project were conducted in 1982, 1985, and 1987. All of them indicated a strongly positive expected net present value of the project. In 1982, the NPV was $\$ 43.2$ million, in 1985 it was $\$ 55.7$ million, and finally in 1987 it was $\$ 41.1$ million - all at 20 percent discount factor.

While the above case studies come from areas as different as public projects (Expo 86), regulated utility industry (Shoreham), software engineering (Config), they do share a certain amount of common features. Projects are started following the receipt of favorable information, expected profits are strongly positive. Positive signals are observed, after which the situation is reversed with a string of negative signals. In the end, the project is either carried through at a loss (Expo 86), or cancelled (Shoreham, Config). The model developed below builds upon these case studies in that it includes decision making under uncertainty with sequential signals received by the manager about the project's likelihood of success.

\section{ESCALATION IN THE REAL OPTION CONTEXT}

Consider the decision problem of an owner-manager of a firm that faces a project selection dilemma under conditions of uncertainty about the project outcome. There are two possible types of projects. The types are different in terms of the outcome. Suppose the possible outcomes are $H$ and $L, H>0, L<0$. The outcome is realized in period $T$. Every period, starting from period 1 until period $T$, the manager receives signals about project's type. The signal takes one of two possible values: $s_{H}$ which is associated with the high outcome project type, or $s_{L}$ associated with the low outcome project type.

$$
\begin{aligned}
& s_{H}: \operatorname{Pr}\left(s_{H} \mid H\right)=p, \operatorname{Pr}\left(s_{H} \mid L\right)=1-q \\
& s_{L}: \operatorname{Pr}\left(s_{L} \mid L\right)=q, \operatorname{Pr}\left(s_{L} \mid H\right)=1-p
\end{aligned}
$$

Existing reputation-based models of escalation (e.g. Kanodia et al., 1989) abstract from the temporal pattern of escalation as the decision maker learns the type of the project with certainty after at most two signals. Case studies, however, emphasized the fact that several negative signals were generally received. The proposed mechanism of Bayesian updating is, thus, better supported by empirical observations. Define the probability of the project being of the high outcome type probability as $\alpha_{t}$.

$$
\alpha_{t}=\operatorname{Pr}\left(H \mid s_{1} \ldots s_{t}\right)=\frac{\operatorname{Pr}(H) \operatorname{Pr}\left(s_{1} \ldots s_{t} \mid H\right)}{\operatorname{Pr}(H) \operatorname{Pr}\left(s_{1} \ldots s_{t} \mid H\right)+\operatorname{Pr}(L) \operatorname{Pr}\left(s_{1} \ldots s_{t} \mid L\right)}
$$

The manager maximizes expected utility. Define the value function of the manager $V\left(\alpha_{t}\right)$ as the expected payoff in period $t$. In the final period $T$, the value of the project is revealed, so the value function is just the value of the project outcome $H$ or $L$. As the real option theory dictates, in period $T-1$, the manager has two choices at his disposal - either continue the project to the completion stage, or terminate the project. The value function of the manager in period $T-1$ can thus be written in the following way.

$$
V\left(\alpha_{T-1}\right)=\max \left[V_{T-1}(\text { Continue }) ; V_{T-1}(\text { Stop })\right]
$$

Define the continuation cost as $c$. Let the cost of terminating the project net of any salvage value be $s$. Let $\beta$ be the discount factor. Recall that the updated probability of the project being a success is $\alpha_{T-1}$. Expression (3) can therefore be rewritten as: 
$V\left(\alpha_{T-1}\right)=\max \left[\beta\left(\alpha_{T-1} H+\left(1-\alpha_{T-1}\right) L\right)-c ;-s\right]$

In period $T-2$, as well as every other period before that, the manager faces three possible choices. Firstly, information search can be continued and another signal can be obtained by incurring a certain search cost. This will presume the continuation of the project to the next period. Secondly, the project can also be continued to completion without looking for new information, based solely on the current probability of success. Finally, the project can be stopped. The value function can be presented as follows.

$V\left(\alpha_{T-2}\right)=\max \left[V_{T-2}(\right.$ Continue $) ; V_{T-2}($ StopSearch $) ; V_{T-2}($ Stop $\left.)\right]$

Define information search cost as $d$. Choice of continuation involves receiving an extra signal and evaluating the value function at the next stage, while if the search is stopped, the project can also be carried through based solely on the current updated value of probability of success $\alpha_{T-2}$. The same three options apply in all previous periods, so in general the value function for period $T-n$ has the below form.

$V\left(\alpha_{T-n}\right)=\max \left[\beta E V\left(\alpha_{T-n+1}\right)-c-d ; \beta^{n}\left(\alpha_{T-n} H+\left(1-\alpha_{T-n}\right) L\right)-\sum_{j=0}^{n-1} \beta^{j} c ;-s\right]$

Calculation of the value function shows the optimal choice for the decision-maker at every stage. The value function depends on the observed path of signals. To calculate the expected values, the distribution of posterior beliefs about project's success and the probabilities of obtaining high and low signals are necessary. At every stage, the decision maker may get one of two types of signal $-s_{H}$, or $s_{L}$. Based on the signal, Bayesian updating will be performed as specified by equation (2). If in period $t$, the current probability of success is $\alpha_{t}$, there are two possible values for $\alpha$ in the next period. The probability of getting a particular signal can also be updated based on the observed sequence of signals. At every time, the probability of getting another high signal $s_{H}$ can be calculated as follows.

$$
p r_{t}=\operatorname{Pr}\left(s_{H} \mid \alpha_{t}\right)=\alpha_{t} * p+\left(1-\alpha_{t}\right) *(1-q)
$$

The value function for the arbitrary period $T-n$ is now specified by (8). Figure 1 shows a graphic representation of the value function for an arbitrary period. There are three components in the value function - the value of continuing the project at current information without information search, the value of stopping (stopping cost), and the value of getting an additional signal. The maximal value of these components comprises the value function. There are three regions in the graph, denoted in Figure 1 as A, B, and C. If the current probability of success lies in region A, it is optimal to stop the project; in region B - continue information search; in region C stop search and continue with the project based on current information.

$$
V\left(\alpha_{T-n}\right)=\max \left[\beta\left(p r_{t} * V\left(\alpha_{t+1}^{H}\right)+\left(1-p r_{t}\right) * V\left(\alpha_{t+1}^{L}\right)\right)-c-d ; \beta^{n}\left(\alpha_{T-n} H+\left(1-\alpha_{T-n}\right) L\right)-\sum_{j=0}^{n-1} \beta^{j} c ;-s\right]
$$

Notice that in terms of the real option theory, the value of the project is analogous to an American call option. The termination cost of the project net of salvage value $(s)$ can be interpreted as the exercise price of the option contract. Continuation of the project to completion is similar to exercising the option. As is well-known from financial theory, the value of the option contract is convex and greater or equal to the maximum of the exercise price and the value of the asset (e.g. Brealey and Myers, 2005).

The model incorporates every objective "project determinant" of escalation mentioned in the review section. Variables such as the size of payoff, the size of continuation costs, the number of successful and unsuccessful "prior commitments" (i.e. the number of positive and negative signals), the sequence of the signals all clearly affect the decision to continue or terminate a project. Staw and Ross (1987) stress the importance of two 
factors - the setbacks being temporary versus permanent and whether a long-term investment is expected. In terms of the model, both factors can be operationalized as changes in the stopping cost $s$ and continuation cost $c$. Suppose we make the continuation cost $c$ a random variable. Then random increases in the continuation cost can be interpreted as the temporary setbacks to the project. In contrast, a permanent setback is a simple shock to the continuation cost.

The solution of the model involves calculation of the distribution of updated probabilities of project success for every possible vector of signals. For an $n$ period model this will involve $2^{n}$ vectors of signals. For each signal vector of size $T$, there will be a vector of $T$ decisions taken in each of $T$ periods. Figure 2 presents a sample distribution of updated probabilities in the form of a "tree" branching after receipt of every additional signal. Viewing the distribution as a "tree" highlights the fact that the distribution in every point depends on the path of observed signals.

\section{Simulation Results}

The focus of this study is on the decision of managers to escalate commitment to a project. As such, it is advantageous to calculate the complete solution to the model and find the optimal decision for every possible sequence of signals, rather than attempt using an option valuation formula. A computer simulation calculated the distribution of updated probabilities of success, and based on them, the value function in every period for all signal paths.

Specific measures of escalation have not been developed in the escalation literature as most theories of escalation are qualitative, and experimental work in escalation of commitment focused only on the relationship between the experimental control variable and continuation decision. Escalation is defined as continuation of a project following negative feedback. It is presumed that escalation is irrational in some sense. The "rational" decision rule is implicitly viewed as continuing the project as long as its updated expected value is positive. However, since past escalation typically did not include the value of the option to terminate the project in the future, this expected value is based solely on the payoffs of a completed project. Let us define escalation as the decision to continue a project following a negative signal when the "myopic" expected value is negative. In terms of the current model, this expected value may be defined as the following expression (9).

$$
E V\left(\alpha_{T-n}\right)=\beta^{n}\left(\alpha_{T-n} H+\left(1-\alpha_{T-n}\right) L\right)-\sum_{j=0}^{n-1} \beta^{j} c
$$

The measure of escalation that will be used below is the probability of observing project continuation following a negative signal. The solution of the model provides a matrix of optimal decisions for every vector of signals. The measure of escalation is thus the sum of probabilities of all signal vectors that lead to escalation decisions. Computer simulations can now be used to investigate the effect of the model's parameters of the measure of escalation. The parameters that will be manipulated include the quality of the signal the manager is getting ( $p$ and $q$ ) as well as the strength of the manager's prior expectation of the success of the project $\alpha_{0}$. Staw and Ross (1989) mention that irregular signals (i.e. signals of worse quality) should lead to escalation. McCarthy et al. (1993) quote psychological theories in predicting that managers with a high level of confidence (that is a stronger prior) escalate more.

Figures 3 and 4 provide the results of numerical solutions of the model for a set of variable parameters. Figure 3 presents the results of simulations for different values of the prior expectation of project success, and Figure 4 reports the results of simulations for different values of signal quality. Both lower prior expectation and better signal quality lead to higher probability of escalation. The following interpretation of the result can be provided. Recall that the value function of the manager consists of three components - the value of continuing the project and getting an additional signal, the value of continuing the project based on the current information, and the value of terminating the project. Since there are information search costs, the choice of continuing the project at current information will always dominate the choice of getting an additional signal, unless there is a chance that on 
the current signal path sufficient information can be gathered to warrant project termination. If there can be a project termination in the future (in Figure 1 this is denoted as Region B), the value function becomes convex, and the information search will not be stopped until the uncertainty about the outcome is resolved. Therefore, any factor that makes additional information more valuable will lead to higher escalation.

Note that escalation in the sense of project continuation following a negative signal when the expected value of project payoff is negative occurs in a large proportion of cases. In the real option framework escalation is not surprising, in fact it is to be expected as the managers try to acquire additional signals to escape uncertainty.

Based on the simulation data, one can compare the decision rule of stopping the project when its "myopic" expected value is below zero with the "escalation" decision rule that takes into account the value of the option of termination in the future. The procedure involves determining all cases when the expected value of the project payoff realization is negative. One can observe what signal path this point is on, and what lies ahead on that signal path. The benefit of following the expected value rule at this point is equal to the stopping cost. The benefit of using the escalation decision rule depends on the ultimate outcome of the project and is the realization of the payoff minus all extra continuation and search costs. The escalation decision rule allows project that would have been cancelled to continue until additional information is received. This rule, thus, decreases Type I error - rejection of projects that are actually of the high payoff type. It also increases Type II error - acceptance of low payoff projects. However, the option value argument ensures that the benefits from reduced Type I errors outweigh the costs of additional Type II errors. The simulation results for the benefits of the two decision rules are presented in Figure 5. The figure shows that the benefits of escalation decision rule are generally positive and non-monotonic for a range of values of the prior probability of success.

The model presented above demonstrates that the use of real option reasoning in project evaluation results in a superior decision rule compared to the conventional net present value of the project's proceeds that ignores the value of having option of project termination. An immediate question is what cases can justify the use of the NPV rule. One example is the existence of a principal-agent relationship with a conflict of interests between the manager and the firm. Suppose the manager gets additional payoff from continuing a project (or does not bear the full cost of erroneous continuation decisions). Then the manager will keep commitment to a project longer than optimal, and instilling an NPV rule may become a safeguard against this process.

\section{Escalation Arising From Correlated Signals}

One widely recognized feature of the escalation process is the fact that decision makers seem unwilling to accept negative information about the project following a string of negative signals. Case studies of Staw and Ross $(1986,1993)$ as well as Keil (1995) indicated this type of behavior on the part of managers responsible for the respective projects. Staw and Ross explain such behavior by calling upon the psychological bias to support one's prior beliefs. A change to the assumptions of the model may explain persistence of managers in pursuing a project and provide an incentive for placing less weight on later signals in a sequence of similar information.

In a setup similar to the model discussed above, consider the project selection problem of an ownermanager of a firm. There are two project types different in terms of the payoff - either high $H>0$ or low $L<0$. The manager chooses one project from a pool. The payoff is realized after $T$ periods. In every period, the manager receives a signal on the type of the project $-s_{H}$ or $s_{L}$ - and decides whether to continue with the project or stop it based on expected utility maximization. There may be a cost of project continuation $c$, for simplicity let us set $c=0$.

The difference from the previous model lies in the structure of signals. The signals can come from one of two processes - either an informative signal-generating process, or an uninformative process that generates correlated signals. The manager observes only the signal, and not the process that generated it. With probability $h_{o}$ the signal comes from process A which is the same as one used before (equation (1)). 


$$
\begin{aligned}
& s_{H}: \operatorname{Pr}\left(s_{H} \mid H\right)=p, \operatorname{Pr}\left(s_{H} \mid L\right)=1-q \\
& s_{L}: \operatorname{Pr}\left(s_{L} \mid L\right)=q, \operatorname{Pr}\left(s_{L} \mid H\right)=1-p
\end{aligned}
$$

With probability $1-h_{0}$ the signal comes from process B - this is the correlated noise component. As "noise" should be, this signal is uninformative.

$$
\begin{aligned}
& \operatorname{Pr}\left(s_{i}=s_{H} \mid s_{i-1}=s_{H}\right)=g \\
& \operatorname{Pr}\left(s_{i}=s_{L} \mid s_{i-1}=s_{L}\right)=g \\
& \operatorname{Pr}\left(s_{1}=s_{H}\right)=\operatorname{Pr}\left(s_{1}=s_{L}\right)=\alpha_{0}
\end{aligned}
$$

In every period, the manager may receive either a high or a low signal. Based on the signal, the probability of project success $\alpha$ will be updated, and with it the value of continuation $V$. The manager can also update the probability $h$ of the signal coming from the informative process A versus the correlated noise process B. As the updating progresses, there is less weight placed on similar signals in sequence, as opposed to differing signals, since similar signals have a higher probability of coming from the correlated noise process. The value of continuing the project is equation (11). As soon as it drops below zero, the project will be stopped.

$$
V_{t}=E\left(\alpha_{t}\right) H+\left(1-E\left(\alpha_{t}\right)\right) L
$$

Consider the distribution of the updated probabilities of success in the "tree" form as was shown in Figure 2. Since strings of similar signals are discounted, less weight is placed on the outside "branches" in this "probability distribution tree". As the termination of a project occurs when the updated probability of success crosses a threshold in the low end of the distribution, and there is less mass in the tails of the distribution, a project may be continued longer than in a case with uncorrelated noise signals. There may be different reasons for correlation in a component of signals. For example, some providers of signals (agents, auditors, consultants) may act consistent with "herding behavior" (Scharfstein and Stein, 1990). In summary, a correlated noise component in signals may lead to escalation when long strings of both positive and negative feedback are discounted, as such strings are less likely to be informative.

\section{Implications For Business}

Escalation of commitment has sparked a heated debate in behavioral and managerial sciences that questioned the basic principles of economic theory and the applicability of economic predictions to project choice decisions. The model presented in this paper demonstrates that escalation-type behavior can be economically rational in a real option context, where escalation is a product of solely the objective project characteristics. The applicability of psychological and organizational theories to the explanation of escalation is not in question. However, an important conclusion of this paper is the need to account for the rational stimuli to "escalate" in cases where irrational escalation is suspected. Rejection of economic basis for escalation leads to overestimation of irrational escalation.

Taking the real option and continuing the project for one period in order to obtain additional information has value for the firm. Simulations results from the option value model of investment demonstrate that likelihood of escalation is higher when signal quality is high, increasing the value of getting an additional signal. Likelihood of escalation also increases when project continuation and termination costs are low, and the amount of potential losses is limited. Continuing the project to receive additional information is shown to be more profitable than the simple net present value rule that excludes option value. This implies that escalation may be value-maximizing for the firm, and managers should not automatically be discouraged to continue a project when new information may appear in the future. 
To some extent escalation may be associated with good projects that did no go as planned. Early termination of a project when the uncertainty about the outcome has not been resolved is not the best course of action. Using a real option decision rule allows project that would have been cancelled to continue until additional information is received. This rule, thus, decreases the rejection of projects that are ultimately successful.

Escalation is not always demonstrative of a mistake by the manager. This may explain the otherwise puzzling fact that managerial compensation does not always suffer when a firm cancels failed projects. In situations of uncertainty, when additional information may be obtained by proceeding with the project, the decision to escalate is rational. This study supports the idea that managers should not be punished for escalation when their behavior is in the best interest of the firm.

\section{REFERENCES}

1. $\quad$ Bachelier, L., 1900. Theorie de la speculation. Annales de l'Ecole Normale Superieure. 17, 21-86.

2. Barron, J., Chulkov, D. and G. Waddell, 2007. The escalation phenomenon and executive turnover. Mimeo, Purdue University.

3. Black, F. and M. Scholes, 1973. The pricing of options and corporate liabilities. Journal of Political Economy. 81, 637659.

4. Bowman, E. and D. Hurry, 1993. Strategy through the option lens: an integrated view of resource investments and the incremental-choice process. Academy of Management Review. 18 (4), 760-782.

5. Brealey, R. and S. Myers, 2005. Principles of Corporate Finance. $6^{\text {th }}$ edition, McGraw-Hill.

6. Brockner, J., 1992. The escalation of commitment to a failing course of action: toward theoretical progress. Academy of Management Review, 17 (1), 39-61.

7. Brockner, J., S. Nathanson, A. Friend, J. Harbeck, C. Samuelson, R. Houser, M. Bazerman, and J. Rubin, 1984. The role of modeling processes in the "knee deep in the big muddy" phenomenon. Organizational Behavior and Human Decision Processes, 33, 77-99.

8. Demange, G., 1992. Rational Escalation. Annales d'Economie et de Statistique, 25/26, 227-249.

9. Dixit, A. and R. Pindyck, 1994. Investment under Uncertainty. Princeton University Press.

10. Goltz, S., 2000. Escalation Research: Providing new frontiers for applying behavior analysis to organizational behavior. Behavior Analyst, 23, 203-218.

11. Kanodia, C., R. Bushman, and J. Dickhaut, 1989. Escalation errors and the sunk cost effect: An explanation based on reputation and information asymmetries. Journal of Accounting Research, 27 (1), 59-77.

12. Keil, M., 1995. Pulling the plug: Software project management and the problem of project escalation. MIS Quarterly, December 1995, 421-447.

13. Keil, M. and J. Mann, 1997. The nature and extent of information technology escalation: Results from a survey of information systems audit and control professionals. IS Audit and ControlJournal. 1, 40-48.

14. Robichek, A. and J. Van Horne, 1967. Abandonment value and capital budgeting. Journal of Finance. $22,577-589$.

15. Ross, J., and B. M. Staw., 1986. Expo 86: An escalation prototype. Administrative Science Quarterly, 31, $274-297$.

16. Ross, J., and Staw, B.M., 1993. Organizational escalation and exit: lessons from the Shoreham Nuclear Power Plant. Academy of Management Journal, 36 (4), 701-732.

17. Scharfstein D. and J. Stein, 1990. Herd behavior and investment. American Economic Review, 80 (3), $465-479$.

18. Shubik, M., 1971. The dollar auction game: a paradox in noncooperative behavior and escalation. Journal of Conflict Resolution, 15, 113-120.

19. Staw, B., 1976. Knee-deep in the big muddy: A study of escalating commitment to a chosen course of action. Organizational Behavior and Human Performance, 16, 27-44.

20. Staw, B.M., and Ross, J., 1987. Behavior in escalation situations: antecedents, prototypes, and solutions. In B.M. Staw and L.L. Cummings (eds.), Research in Organizational Behavior, vol. 9. Greenwich, CT: JAI Press, 1987, pp. 39-78.

21. Staw, B.M., and Ross, J., 1989. Understanding behavior in escalation situations. Science, 246, 216-220.

22. Tiwana, A., M. Keil, and R.G. Fichman, 2006. Information Systems Project Continuation in Escalation Situations: A Real Options Model. Decision Sciences, 37 (3), 357-391. 


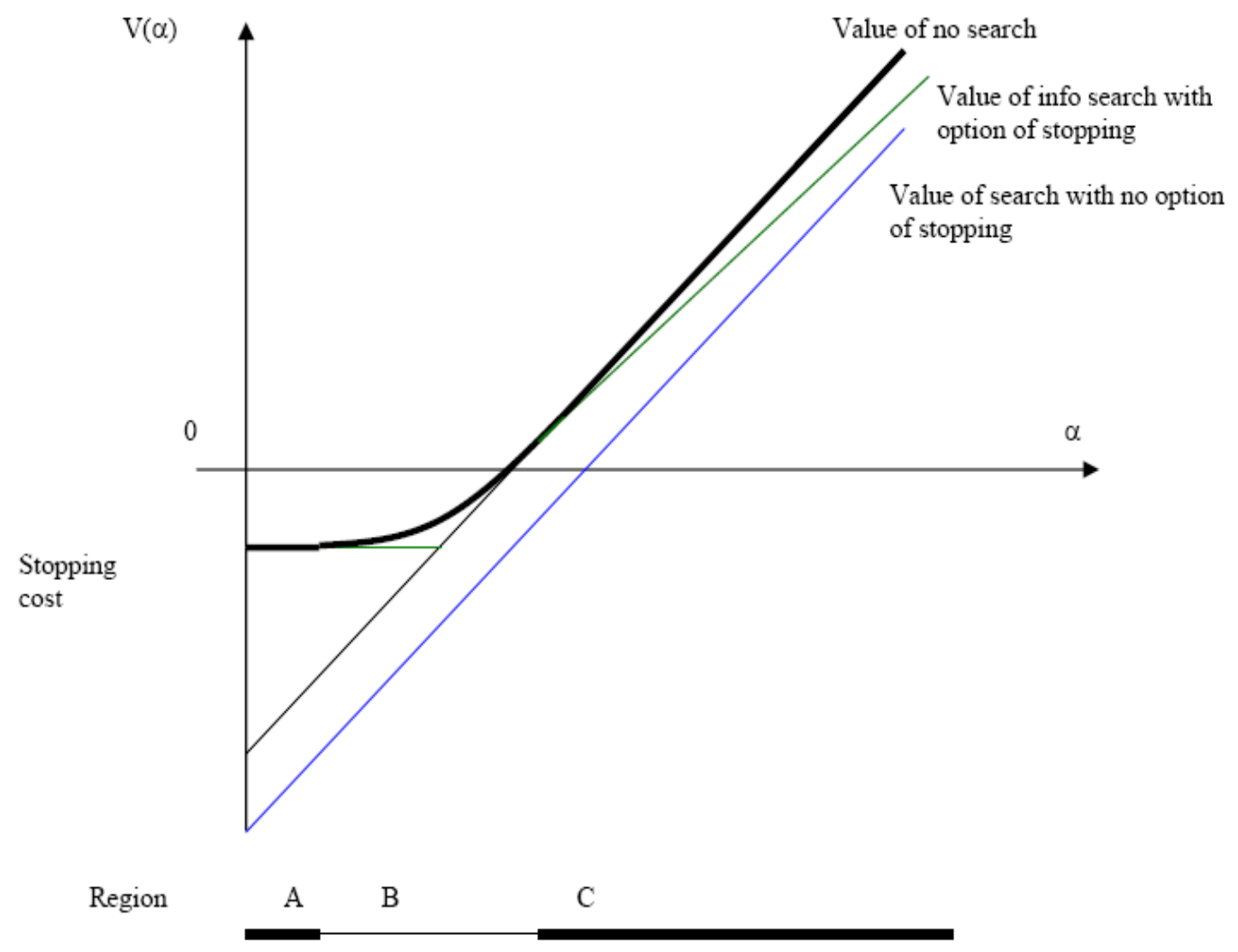

Figure 1: Value function for an arbitrary period. 


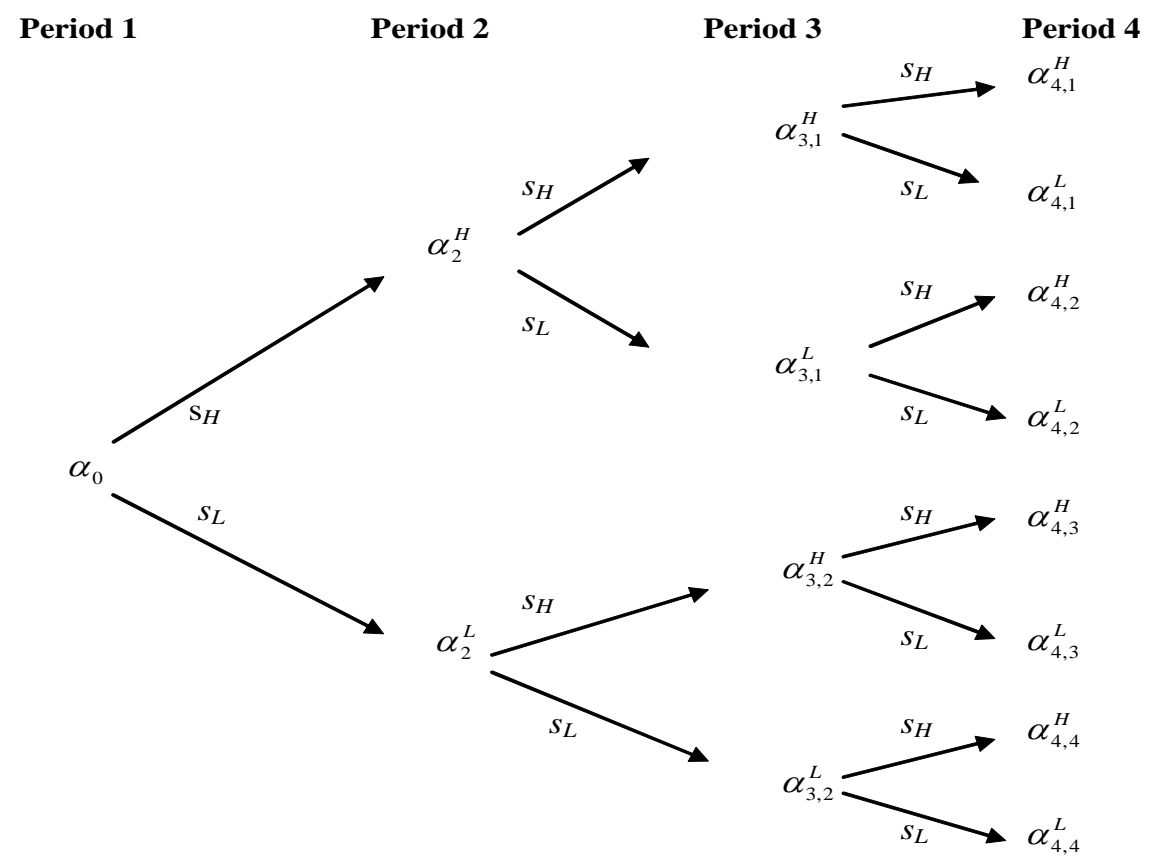

Figure 2: Distribution tree of the updated probability of success.

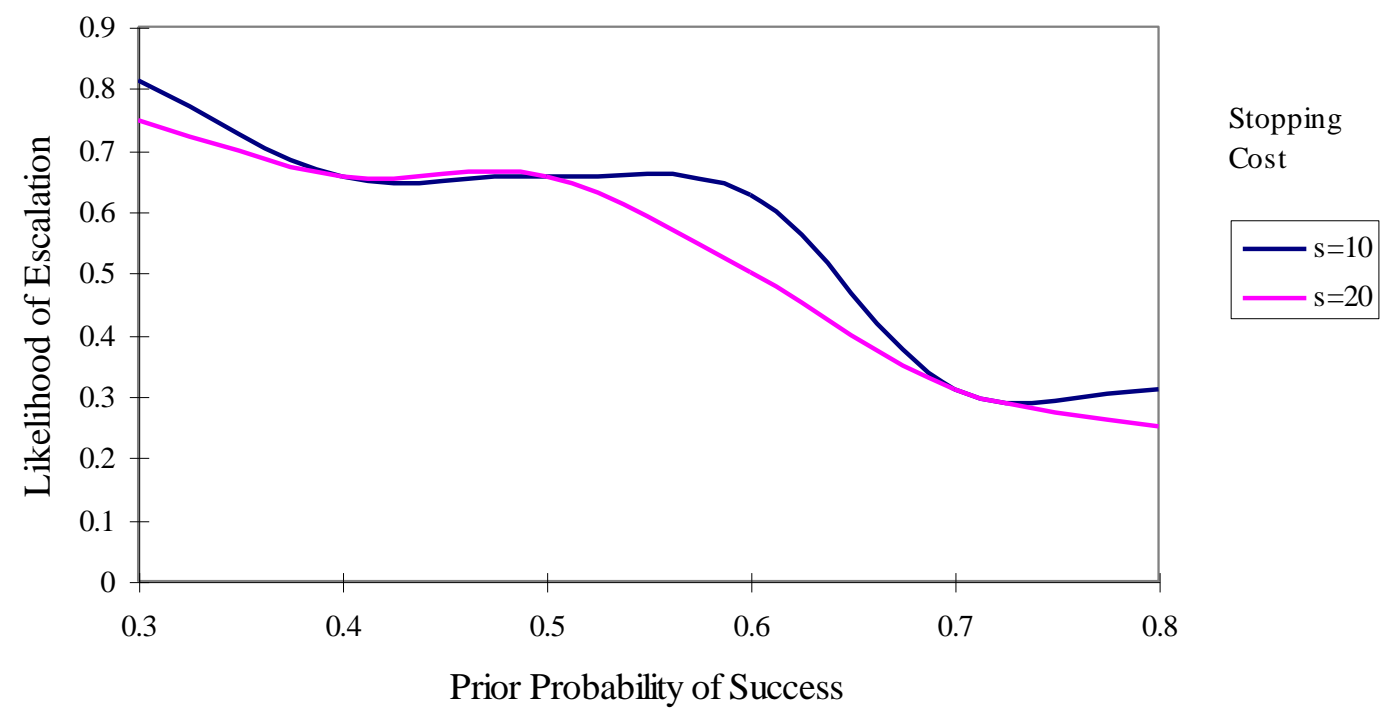

Figure 3: Escalation and the prior expectation of success in simulations.

The actual ex ante probability of success of a project was 0.5 . Two levels of stopping cost are shown ( $\mathrm{s}=10$, and $\mathrm{s}=20)$. The simulations were conducted for the following parameter values $\mathrm{H}=200, \mathrm{~L}=-100, \mathrm{p}=0.85, \mathrm{q}=0.85, \mathrm{~d}=2, \mathrm{c}=3, \beta=0.9, \mathrm{~T}=6, \gamma=0.5$. 


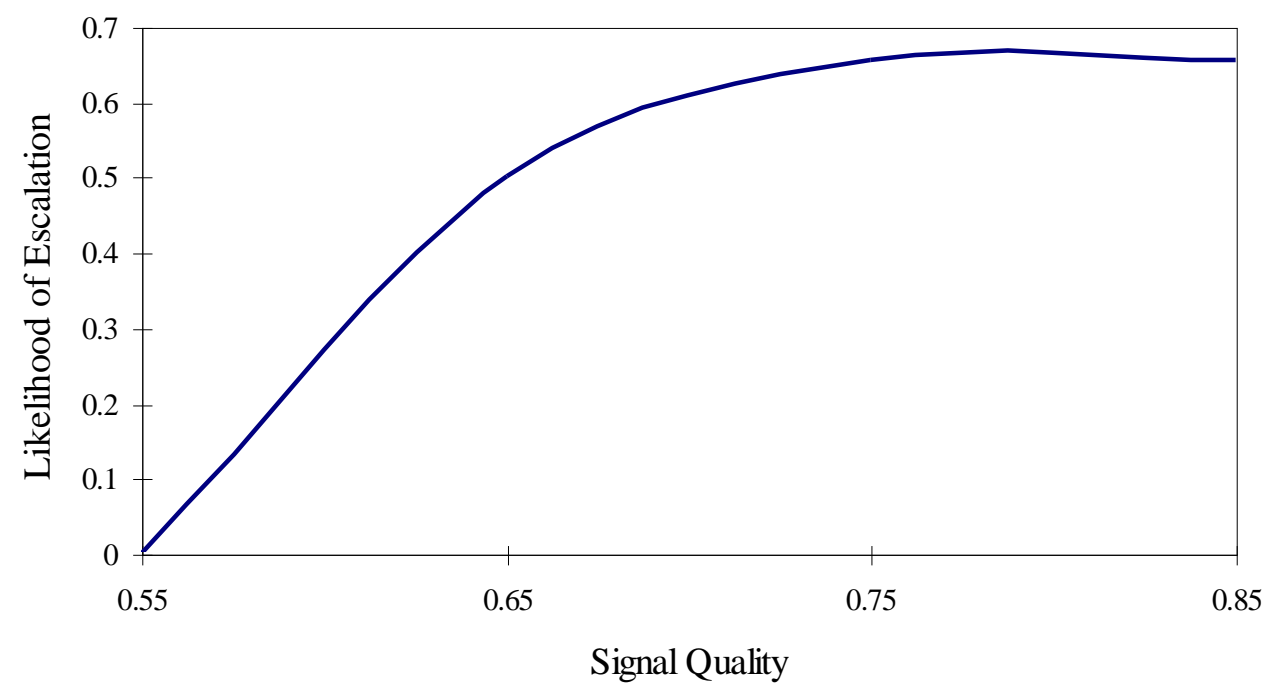

Figure 4: Effect of signal quality on likelihood of escalation in simulations.

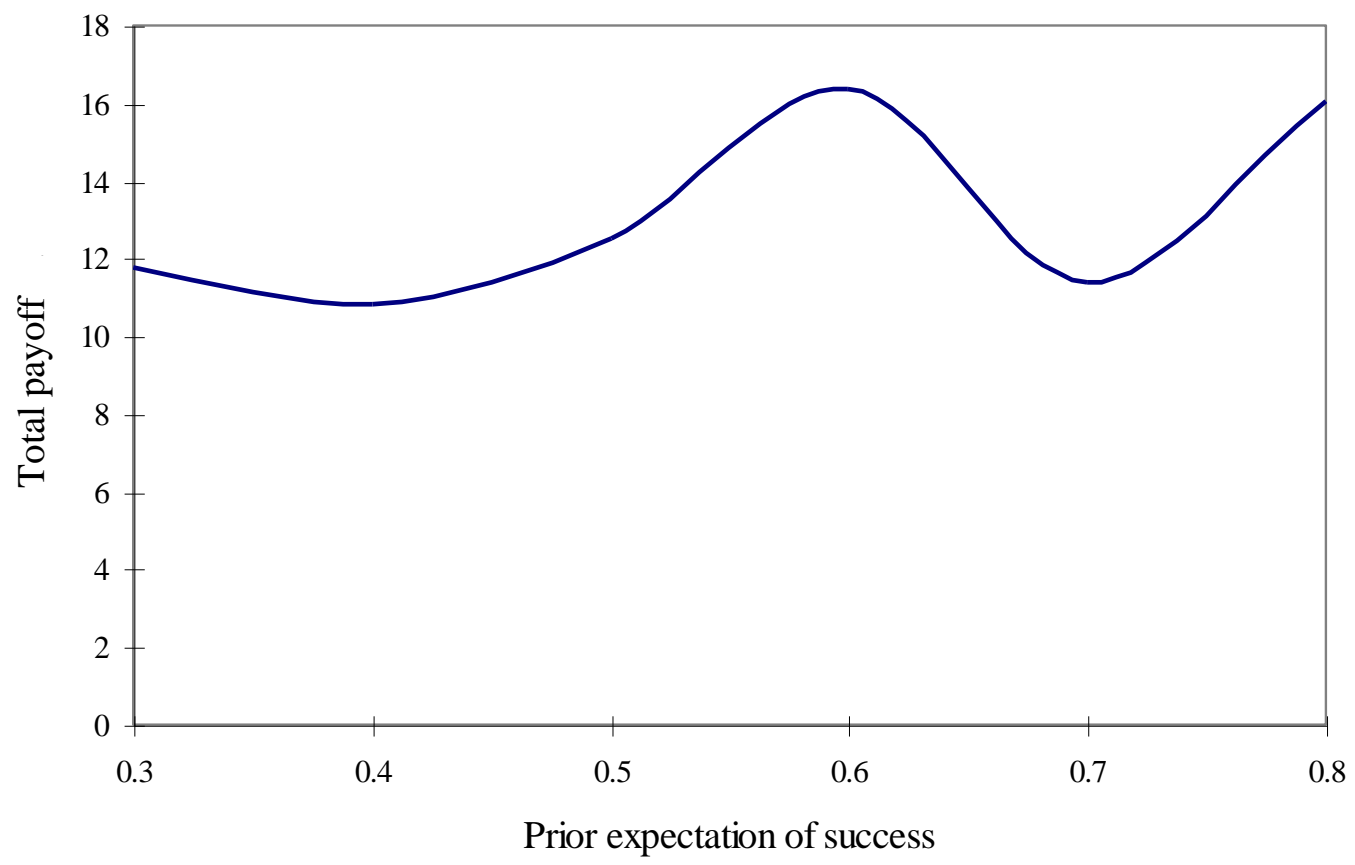

Figure 5: Net benefit of the "escalation" decision rule in simulations. 
NOTES 